\title{
Literatura, tradução e cultura: intersecções teóricas sob um olhar sistêmico
} Literature, translation and culture: theoretical intersections under a systemic view

\author{
Valéria Brisolara \\ Universidade do Vale do Rio dos Sinos - Unisinos - Rio Grande do Sul - Brasil
}

\section{Lilia Baranski Feres}

Centro Universitário Ritter dos Reis- UniRitter - Rio Grande do Sul - Brasil

\begin{abstract}
Resumo: Tomando a literatura e a tradução como práticas inerentemente sociais e culturais, o presente artigo tem por objetivo discorrer e refletir acerca de abordagens teóricas contemporâneas que lançam um olhar sistêmico sobre as instâncias de produção, recepção e circulação da literatura, reservando um espaço para tratar particularmente dos processos que circundam a internacionalização da literatura. Tendo em vista que a literatura traduzida é subcampo usualmente com menos destaque no vasto campo literário, o estudo espera contribuir para a compreensão dos processos culturais envolvidos nos ciclos que geram a concretude dos textos, de modo a influenciar na sua elaboração enquanto ofertas de leitura (seja ela nacional ou traduzida) e enquanto bens literários/simbólicos.
\end{abstract}

Palavras-Chave: Literatura; Tradução; Cultura; Campo literário; Polissistema literário.

Abstract: Taking literature and translation as inherently social and cultural practices, this article aims at discussing and reflecting on contemporary theoretical approaches that hold a systemic perspective on the instances of production, reception, and circulation of literature, reserving a part of it to deal particularly with processes which surround the internationalization of literature. Bearing in mind that translated literature is usually a subfield with less prominence in the vast literary field, the study hopes to contribute to the understanding of some of the cultural processes involved in the cycles that generate the concreteness of texts, in order to influence their elaboration as reading offers (either national or translated) and as literary/symbolic goods.

Keywords: Literature; Translation; Culture; Literary field; Literary polysystem. 


\section{INTRODUÇÃO}

A cultura se expressa de distintas formas ao longo do tempo e do espaço e essa multiplicidade se manifesta, dentre outros modos, na originalidade e na diversidade das produções literárias. A literatura se constitui, portanto, como prática social e cultural de apropriação, compreensão e elaboração de sentidos. A tradução, particularmente, se apresenta como ferramenta primordial que possibilita tanto o diálogo intercultural quanto a salvaguarda da diversidade linguística. No entanto, a literatura traduzida, e, por conseguinte, a tradução, acabam recebendo menos destaque no vasto campo literário na medida em que muitas vezes não se menciona que uma obra é uma tradução, quem a traduziu e qual o seu contexto de tradução.

Considerando a cultura como valor simbólico, como direito à cidadania e como elemento da economia, a partir da noção de capital cultural, torna-se mais fácil se desprender da visão reducionista do livro como objeto cultural insulado. Por isso, a proposta teórica aqui em questão explora vertentes teóricas contemporâneas (BOURDIEU, 1996; EVEN-ZOHAR, 1990; CASANOVA, 2002) com o intuito de alargar o entendimento das instâncias envolvidas na manufatura dos textos, do caminho percorrido por esse produto até atingir seu estado de bem simbólico e cultural disponível para leitura nas prateleiras (físicas ou virtuais), encorajando uma perspectiva sistêmica e em diálogo com as manifestações atuais. Assim, este artigo tem por objetivo discorrer e refletir acerca de abordagens teóricas contemporâneas que lançam um olhar sistêmico sobre as instâncias de produção, recepção e circulação da literatura, reservando um espaço para tratar particularmente dos processos que circundam a internacionalização da literatura, que, inevitavelmente, envolvem instâncias de tradução.

\section{Campos e Forças}

Refletir sobre a internacionalização da literatura brasileira não é considerar somente de tradução. Embora ela seja um importante caminho, também precisamos ter em mente que os livros, enquanto produtos literários, assim como outros artigos culturais (filme, música, telas, esculturas, etc.), são bens que igualmente ingressam no ciclo econômico que, por sua vez, dependem de outros elementos. Bourdieu (1996) explora a complexidade dessas relações a partir do que ele denomina campo, que pode se desdobrar em diversos outros campos, como o do poder, o da ciência, o da arte e o literário.

Para Bourdieu, o campo literário se encontra subordinado ao campo de poder, sendo este último um "espaço das relações de força entre agentes ou instituições que têm em comum possuir o capital necessário para ocupar posições dominantes nos diferentes campos (econômico e cultural, especialmente) (BOURDIEU, 1996, p. 244). O campo seria uma complexa rede de relações objetivas, sejam elas de dominação ou de subordinação, de complementaridade ou de contraposição, entre posições. Em outras palavras, o campo de poder consistiria na arena de lutas entre detentores de poder, onde o princípio formador e delimitador desse sistema é o próprio conflito.

De forma análoga, o campo literário seria um espaço cujas posições de seus agentes são pré-fixadas, onde uma disputa entre seus integrantes é travada em torno de interesses específicos; neste caso, os que competem ao campo literário. Trata-se de um universo que obedece às suas próprias regras de funcionamento e de modificação, isto é, de uma "estrutura das relações objetivas entre as posições que aí ocupam indivíduos ou grupos colocados em situação de concorrência pela legitimidade" (BOURDIEU, 1996, p. 243). Ainda, consiste num espaço parcialmente autônomo, já que depende, ao menos em parte, de suas interações com os campos econômico e político, cuja lógica específica é assegurada pela natureza própria dos bens simbólicos, cujos valores simbólico e mercantil oscilam de forma relativamente independente. É nesse campo que as relações de poder se manifestam e o estudo dessas relações (seja qual for o campo) e das estratégias empregadas pelos agentes que o integram (e os caracterizam), nos fornecem informações sobre como a sociedade se transforma e se conserva. Devido a essa natureza, é importante frisar que o campo não pode ser tomado como um espaço exclusivamente resultante das ações individuais de seus atores. 
Em função das associações de poder, o campo literário é regulado por meio da difusão desequilibrada do que Bourdieu (1983) denomina quantum social ou capital social, uma espécie de patrimônio capaz de estabelecer a posição que determinado agente ocupa no campo. Esse capital pode ser de um tipo menos abstrato - capital econômico - ou mais abstrato - capital simbólico. Assim, o campo literário se organiza em torno de dois polos antagônicos: o dos ditos dominantes e o dos ditos dominados. O que determina a posição de cada um dos agentes dentro do campo é a quantidade de capital social (econômico e simbólico) que ele detém. Aqueles que possuem capital social em abundância compõem o polo dos dominantes; aqueles que carecem desse capital integram o polo dos dominados.

Assim, sob a ótica Bourdiana, a sociedade pode ser apreendida como estratificação de poder, com seus próprios meios de legitimar os bens simbólicos e de filtrar os integrantes que podem ascender na hierarquia cultural. Os modos de consumo dos bens simbólicos oferecidos no mercado são determinados por meio dos capitais econômico e cultural de que dispõem, podendo ser mensurados a partir do tipo de emprego, do acesso ou não à escola, por exemplo (entre tantas outras características, obviamente). O campo literário é um campo de lutas cujo objetivo primordial é a conquista ou a preservação do domínio. Embora nem sempre estejamos conscientes da nossa participação nessa disputa, existimos socialmente, ou seja, ocupamos uma posição específica na estrutura social e expressamos suas marcas; nos sujeitamos às suas determinações e aos seus limites, manifestados, sobretudo, através de automatismos verbais e de mecanismos mentais. As traduções ocorrem dentro desse campo literário e as escolhas do que traduzir e de como traduzir estão sujeitas às suas forças.

Um dos teóricos que dialoga com a teoria de Bourdieu é o sociólogo, linguista e crítico israelense Itamar Even-Zohar, para quem o (macro)campo corresponderia ao polissistema (1990), isto é, um sistema múltiplo, dinâmico e heterogêneo, composto por vários sistemas interligados uns aos outros e parcialmente sobrepostos que utilizam opções simultaneamente distintas, do qual faz parte o polissistema literário. À luz dessa teoria, um sistema seria um complexo de atividades, ou qualquer parte dele, sobre o qual relações sistêmicas possam ser hipotetizadas (EVEN-ZOHAR, 1990, p. 85). Embora a teoria dos polissistemas tenha sido motivada sobretudo pelas questões em aberto relacionadas à literatura, é uma teoria não necessariamente se restringiria apenas a tal âmbito, podendo, vez ou outra, dar conta de problemáticas mais amplas do que às da literatura. Como o próprio nome sugere, os fundamentos de Even-Zohar não tomam a literatura como uma atividade isolada na sociedade, regulada por leis exclusivamente e inerentemente distintas das demais práticas humanas. Pelo contrário, a literatura é concebida como uma atividade integral, inclusive frequentemente central e bastante poderosa, desse sistema. Dentro dessa perspectiva, a teoria dos polissistemas também pode ser uma importante chave para compreender as correlações existentes entre repertório e sistema, ou entre produção, produto e consumo. Trata-se de um arcabouço teórico que considera tanto as conexões quanto as desconexões entre as diferentes partes que integram o complexo, representando um passo além das teorias limitadas a registrar e classificar os fenômenos literários e indo em direção à detecção das leis que orquestram a diversidade e a complexidade desses fenômenos. Por esse motivo, não devemos pensar no polissistema como um centro e uma periferia, visto que tais posições são hipotetizadas e não existe somente um centro ou uma periferia, como inicialmente se considerou. Hipoteticamente, um movimento poderia se dar por meio de um determinado item (um elemento ou função, por exemplo) transferido da periferia de um sistema para a periferia de outro sistema subjacente dentro do mesmo polissistema e, com isso, poderia ou não se alocar no centro dele. Em termos de estruturação desse complexo, Even-Zohar segmenta o polissistema literário em instituição, repertório, produtor, consumidor, mercado e produto, representando os macro fatores envolvidos com o funcionamento do sistema literário (1990, p. 31). Esses macro fatores encontram-se todos interligados entre si e, por esse motivo, são influenciadores uns dos outros.

Para Even-Zohar (1990), a instituição corresponderia ao composto de elementos envolvidos 
com a manutenção da literatura enquanto atividade social, sendo a parte responsável por regulamentar as normas vigentes nesse escopo; sua função consiste em sancionar e rejeitar normas. Legitimada por outras instituições (ou até mesmo sendo parte delas), é capaz de alavancar ou censurar produtores e agentes. Por ser parte "oficial" da cultura, igualmente determina quem e quais produtos serão preservados pelo público. A instituição pode abranger, ao menos em parte, produtores, críticos, editoras, periódicos, clubes, grupos de escritores, órgãos governamentais (ministério da cultura/educação, academia de letras), instituições educacionais (de qualquer nível de educação), mídia de massa, entre outros (EVEN-ZOHAR, 1990, p. 37). De forma análoga ao campo (BOURDIEU, 1996), dentro da instituição ocorrem lutas pela dominação, com oscilação entre os grupos que tomam o poder e ocupam seu centro e, dessa forma, a função de autoridade.

O repertório consistiria no conjunto de leis e elementos, sejam eles modelos únicos, parciais ou totais, que regulam não apenas a produção de textos, mas também o uso de qualquer produto, sendo indispensável para qualquer processo de produção e consumo. $\mathrm{Na}$ medida em que pode ser compreendido como a combinação de gramática e léxico de uma determinada língua, o repertório passa a ter conhecimento prévio e acordos (linguísticos) como noções chaves, no sentido em que um conhecimento compartilhado se faz necessário para a produção e compreensão de um texto, assim como para a produção e compreensão de diversos outros produtos oriundos do sistema literário. Para EvenZohar, um sistema dito "jovem" pode apresentar um repertório limitado, sendo, por isso, mais propenso a beber de outros sistemas (utilizando, por exemplo, outras línguas, culturas, literaturas); já um sistema dito "antigo" pode ter acumulado um rico repertório e, por tal motivo, estar mais inclinado a apenas reciclar suas estruturas vez ou outra (1990, p. 40). O emprego de repertório, poderia se dar em três níveis: a nível de elementos individuais, o que inclui itens isolados como morfemas e lexemas; a nível de sintagma, incluindo qualquer combinação até o nível de uma frase; ou a nível de modelos, incluindo qualquer potencial combinação de um produto inteiro, ou seja, combinação de elementos, regras e sintagma (EVEN-ZOHAR, 1990, p. 41).

O produtor, representado pela figura do escritor (que carrega consigo crenças muito específicas que podem, muitas vezes, ser imprecisas), luta para que seu texto seja reconhecido e aceito como parte do cânone, ou ao menos que seja tomado como uma manifestação bem-sucedida de um modelo legitimado. Esse agente está vinculado a um discurso de poder formulado segundo um repertório aceitável e legitimado. Embora Even-Zohar tenha estratificado o sistema literário em macro funções, elas não operam de forma isolada. Os produtores, por exemplo, nem sempre se limitam a apenas uma função dentro dessa rede, podendo (ou sendo impelidos a) participar em diferentes atividades (que podem ser ingenuamente tomadas como isoladas), que podem até mesmo ser conflitantes umas com as outras (mesmo que em parte). Assim, o que se vê não são somente escritores isolados ou grupos isolados de escritores, mas sim grupos ou comunidades, das quais os escritores - produtores - fazem parte, dedicados à produção, aparelhados de várias formas e se relacionando entre si tanto quanto com seus consumidores em potencial. São agentes que circulam por outras esferas do sistema literário.

Dentro da perspectiva dos polissistemas, o consumidor corresponderia ao público. O consumo, entretanto, tal qual a produção, não está restrita somente à leitura de textos. O consumidor, assim como o produtor, é capaz de transitar por diversos níveis como agente da atividade literária. Even-Zohar defende que todos os membros de qualquer comunidade são ao menos consumidores indiretos de textos literários, visto que consumimos determinadas quantidades de fragmentos literários, digeridos e transmitidos por vários agentes culturais, e incorporados em nosso discurso cotidiano (1990, p. 36). Já para os ditos consumidores diretos (pessoas voluntariamente interessadas nas atividades literárias), existe a possibilidade de estarem mais interessados em participar das atividades adjacentes à literatura do que ler por si só. Tal hipótese se justifica pelo fato de muitos consumidores de literatura frequentemente consumirem as funções socioculturais das práticas implicadas nessa atividade, muitas vezes mais do que 
seu próprio "produto" (EVEN-ZOHAR, 1990, p. 36). Esse padrão pode ser detectado quando um "leitor" opta por encontrar um renomado escritor mesmo sem ter lido sua obra, com o objetivo maior de colher um autógrafo em um livro que jamais será fruído. Por razões como essa, o consumo de textos pode ser somente um aspecto do consumo literário em geral.

O mercado consiste no conjunto de fatores envolvidos com a venda e compra de produtos literários, assim como com a promoção de padrões de consumo, seja através de instituições mais óbvias de troca de mercadorias como livrarias, clubes literários ou bibliotecas; por meio daqueles aspectos pertencentes à troca semiótica - simbólica - envolvida; ou por outras atividades afins. Novamente, dentro desse contexto sociocultural, vemos práticas entre subcampos se cruzarem. Práticas da instituição literária podem se sobrepor às do mercado literário, como é possível observar nos salões (literários) e nas escolas, que exercem tanto função de instituição quanto de mercado (EVEN-ZOHAR, 1990, p. 38-39). Obviamente, por questões econômicas e políticas, o intuito do sistema literário é ampliar, cada vez mais, seu mercado.

Embora haja um primeiro impulso que nos faça pensar no texto como o principal - ou único - produto do sistema literário, Even-Zohar insiste no contrário, ou seja, que o texto não pode mais ser o único, ou necessariamente o mais importante, resultado ou até mesmo produto desse sistema (1990, p. 33). Tanto o texto quanto o repertório são apenas manifestações parciais da literatura, cujos comportamentos não podem ser explicados por sua própria estrutura. É para tentar dar conta desses funcionamentos que a teoria, a nível de (polis)sistema literário, emerge. $\mathrm{O}$ autor compreende $\mathrm{O}$ produto do sistema literário mais no sentido de consequência, podendo, portanto, ser qualquer conjunto de signos apresentado ou apresentável, até mesmo um certo comportamento. Deste modo, qualquer resultado de qualquer atividade, independentemente de sua manifestação ontológica, poderia ser tomado como um produto (EVEN-ZOHAR, 1990, p. 43).

Após percorrermos os fatores envolvidos no (polis)sistema literário e compreende-los melhor, é possível observar a interdependência entre os fatores, motivo pelo qual são capazes de operar como tal. De forma geral, vislumbramos a seguinte dinâmica: um consumidor busca adquirir em um mercado um bem produzido por um produtor, mas para que esse produto (materializado na forma de um texto, por exemplo) possa ser criado, um repertório comum deve existir, cuja usabilidade é determinada por alguma(s) instituição(ões). É relevante reiterar que nenhum desses elementos opera de forma independente e os tipos de interação observáveis nesse complexo podem ocorrer em todos os sentidos possíveis, sendo possível estabelecer uma relação de equivalência entre o conceito de polissistema, no qual interações e mudanças operam, e as noções de campo e subcampo, nos quais forças e trocas atuam.

\section{A força da literatura traduzida no} intercâmbio de bens simbólicos

As indagações basilares da teoria dos polissistemas circundam a motivação das transferências entre determinados bens e sistemas, abrangendo os sistemas nacional e internacional quando falamos em exportação de literatura por meio da tradução. Parte da teoria de Even-Zohar é dedicada ao segmento de literatura traduzida e possui particular relevância.

Via de regra, a história da literatura só reserva espaço para esse segmento quando é inevitável. Consequentemente, pouco se reconhece sobre a dimensão de sua função na literatura como um todo ou de sua posição dentro de uma literatura. Mais preocupante ainda é o fato de, muitas vezes, a literatura traduzida sequer ser cogitada como um sistema literário particular. Na contramão desse pensamento, o teórico israelense reitera que a literatura traduzida não somente compreende um sistema completo inserido no sistema literário, como se trata do sistema mais ativo dele, cuja principal função tem sido relacionada à solidificação de culturas nacionais (EVEN-ZOHAR, 1990, p. 45). A literatura traduzida teria uma posição central no polissistema literário, participando ativamente na configuração de seu centro e sendo, na maioria das vezes, uma frente dos movimentos de inovação, pois quando novos modelos literários surgem, a tradução pode ser uma das formas de elaboração de novos 
repertórios. Essa elaboração se dá através da introdução de trabalhos estrangeiros, novos modelos poéticos, padrões, técnicas, elementos ou léxico na literatura de chegada, na qual tais modelos não existiam. $\mathrm{Na}$ realidade, o próprio processo de seleção das obras a serem traduzidas é determinado pela conjuntura apresentada pelo polissistema de chegada, pois os textos são apontados conforme a compatibilidade com as novas tendências e com o potencial papel de inovação que a obra pode desempenhar ao ser inserido na literatura de chegada. Observada mais isoladamente, como um sistema em si, a literatura traduzida se mostra igualmente estratificada, sendo possível que uma fração dela assuma o centro, enquanto outra adote uma posição menos central. Em função dessas dinâmicas e da própria sujeição da prática tradutória à sua posição (e seu status) no sistema literário, fica evidente que a tradução não pode ser compreendida como uma atividade cujos limites e natureza são claros e estanques, mas sim uma prática extremamente dependente das relações que se estabelecem dentro de determinado sistema cultural. Assim, torna-se patente a imposição, pelo polissistema, de limitações e pressões sobre os modos de selecionar, manipular, amplificar e excluir, observados em seus bens reais (EVEN-ZOHAR, 1990). Considerando que certos textos (e repertórios) pertencem ao cânone enquanto outros pertencem às margens, criam-se territórios para tensões entre as posições mais centrais e mais periféricas do sistema.

Essas disputas por reconhecimento seriam travadas em um território denominado República Mundial das Letras (CASANOVA, 2002), espécie de mercado mundial de bens intelectuais. Pelo fato de os limites desse universo literário não se sobreporem plenamente aos do universo político e econômico, a república apresenta uma forma característica de operar, uma economia particular, movimentada por sua própria moeda de troca, o capital literário, valor particular de cada autor, língua, literatura. Essa economia, assim como qualquer outra, resulta em hierarquias e, por sua vez, em violências. É por isso que a crítica literária francesa Pascale Casanova (2002) entende a história da literatura como a história das rivalidades cujo objeto de desejo é a literatura; conflitos sustentados por renúncias, manifestos, opressões, revoltas, desvios, movimentos literários, delineando a literatura mundial. Nesse cenário movido pelo capital literário, a idade é uma característica crucial na determinação desse capital. Quanto mais antiga for a literatura, mais importância terá seu patrimônio nacional, mais obras canônicas ela exibirá, obras que, rotuladas como clássicos nacionais, representam o panteão nacional e atingem a escola e outras instituições. $O$ dito clássico passa a ser uma unidade de medida singular na validação de outros textos, balizando o que pode ou não ser considerado como literário (CASANOVA, 2002, p. 30). A antiguidade de uma literatura, entretanto, não é o único fator a influenciar seu capital. A língua constitui um dos principais elementos dele e a partir da qual princípios de dominação políticos (entre outros) são exercidos. Dentro do universo literário, há idiomas conceituados como mais ou menos capazes de expressar-se literariamente, fazendo com que seus textos tenham mais (ou menos) prestígio e ostentem uma espécie de certificado literário. Grego e latim já desfrutaram desse poder; francês e alemão ainda o fazem. As literaturas não são, destarte, a manifestação de uma identidade nacional, elas se constituem na concorrência e nos embates literários. Por esse motivo, as relações de força do universo literário são permeadas, em grande parte, pelas tensões políticas e econômicas (CASANOVA, 2002, p. 107).

A república mundial das letras pode, então, ser compreendida como um espaço parcialmente íntegro, organizado segundo a polarização entre os grandes campos literários nacionais, aqueles mais antigos e, por isso, mais abastecido de capital, e os campos literários mais recentes e, por essa razão, menos abastecidos de capital. Contudo, o mundo literário não se resume a um trivial antagonismo entre espaços dominados e espaços dominantes. Casanova fala de um continuum, onde "as oposições, as concorrências, as formas de dominação múltiplas impedem o esboço de uma hierarquia linear" (2002, p. 110). Essa existência de tensões entre literatura/cultura canônica e não canônica é universal, pois está presente em todos os ramos da cultura humana. Even-Zohar defende que simplesmente não há sociedade humana que não seja estratificada (1990, p. 16). O mundo literário obedece a uma lógica particular, 
ignorando o espaço geográfico e criando novos territórios e divisas. Trata-se de longos processos históricos ao longo dos quais se adquire autossuficiência e se constrói um patrimônio literário. Essa trajetória, por sua vez, "pode fazer com que se esqueça o laço histórico muito forte que une literatura e nação no momento da fundação nacional, produzindo assim, a crença de uma literatura completamente pura, liberada da história" (CASANOVA, 2002, p. 114), eclipsando a raiz política da literatura.

Apesar dos graus de subordinação, o universo literário não possui uma estrutura inalterável em suas relações hierárquicas. Embora o provimento desigual de capital literário provoque condições de dominação resistentes, o espaço literário é o lugar de lutas ininterruptas, de denegação da soberania e da legitimidade, de revoltas, de insubordinações e inclusive de revoluções literárias mais ofensivas, capazes de alterar as relações de poder e de gerar um revés na hierarquia vigente. É por isso que para Casanova, "a única história real da literatura é a das revoltas específicas, dos atos de violência, das invenções de formas e de línguas, de todas as subversões de ordem literária que aos poucos fazem a literatura e o espaço literário" (2002, p. 217). Quando pensamos em um espaço dominante, pode ser difícil enxergá-lo como dominado em algum momento da história. Entretanto, todos os campos literários já estiveram na condição de dominado em algum momento de sua construção. $O$ espaço literário internacional se constituiu por meio das disputas dos inúmeros personagens que buscavam ingressar nesse jogo das letras. Sob a perspectiva dos anais e da origem do universo literário mundial, a literature

é uma espécie de criação, ao mesmo tempo, irredutivelmente singular e no entanto inelutavelmente coletiva, de todos os que criaram, reinventaram ou se reapropriaram do conjunto das soluções disponíveis para mudar a ordem do mundo literário e a univocidade das relações de força que o governam: novos gêneros literários, formas inéditas, novas línguas, traduções, literarização dos usos populares da língua, etc. (CASANOVA, 2002, p. 218)
A configuração desequilibrada que caracteriza a república mundial das letras constantemente confronta espaços literários ditos grandes aos pequenos, sujeitando os escritores a lutas ferrenhas e nem sempre justas em busca de uma melhor colocação. Essa dinâmica é responsável pela legitimação da canonicidade e do capital dos escritores e de suas obras. Quanto mais canônico seu nome for, maior será seu capital. Como mencionado anteriormente, tal valor se constrói também por meio da força da língua, elemento igualmente detentor de capital literário, oriundo de seu poder político e econômico. Embora o português seja a sexta língua mais falada (em número de falantes), a quantidade de locutores é insuficiente para legitimar a hierarquia entre línguas centrais e periféricas (SONCELLA, 2012). A posição mais periférica de nosso idioma acaba se tornando uma barreira para a difusão de nossas obras mundo afora. E em virtude do baixo capital simbólico que a língua possui enquanto língua literária, o país goza de limitada autonomia no cenário literário global, o que, por sua vez, dificulta sua projeção internacional. Trata-se de um circuito em que uma questão realimenta a outra. Quebrar esse fluxo torna-se um desafio. Em função disso, é pertinente salientar que em territórios incorporados ou dominados politicamente, a literatura pode se revelar uma arma de luta ou de resistência nacional. Incumbidos da missão de fixar uma originalidade intransferível, de instituir uma língua ou viabilizar uma cultura nacional singular, os escritores colocam a escrita a serviço da nação e do povo. A literatura se converte em nacional/popular "a serviço da ideia nacional, encarregada de colocar a nação na categoria de todas aquelas que têm existência e reconhecimento literários" (CASANOVA, 2002, p. 236). Já o processo de independência literária depende de um mínimo de recursos e de autonomia política acumulados, e para que tal processo de acumulação literária ocorra é preciso um personagem principal que exerça esse papel de forma meticulosa e clara, isto é, um escritor que faça do conteúdo popular um material literário. Para Casanova, a principal missão desses escritores, na função de fundadores da literatura, é, de certo modo, "fabricar a diferença" (2002, p. 238), aquilo que pode ser crucial na luta entre dominantes e dominados. 
Nesses processos em busca da fabricação da diferença, podemos observar a consagração de uma obra como "uma metamorfose quase mágica de um material comum em 'ouro', em valor literário absoluto" (CASANOVA, 2002, p. 162). Nessa transmutação, as esferas de validação são as responsáveis por preservar, assegurar e gerar o valor, viabilizando uma transição da "inexistência à existência literária, da invisibilidade ao estado de literatura" (ibidem), transformação que Casanova (2002) chama de literarização. A prática tradutória desempenha uma função particularmente importante nesse processo, pois constitui-se uma instância de consagração crucial no mundo das letras. $\mathrm{Na}$ condição de porta de entrada para a literatura universal, é muito mais do que somente uma conversão de língua, é um meio de certificação literária. Essa aparentemente simples transferência linear é o principal estímulo e a ferramenta chave na disputa literária internacional, "instrumento de geometria variável cujo uso difere de acordo com a posição do tradutor e do texto traduzido" (CASANOVA, 2002, p. 169) ou, nos dizeres de EvenZohar (1990), conforme a posição das línguas de chegada e de partida. Nesse contexto de tradução, o tradutor passa a ser um mediador que possibilita 0 intercâmbio (i)material mundial e o avanço desse comércio.

Para as chamadas línguas alvo, o processo tradutório é um meio de acumular recursos literários, de trazer obras internacionais de renome para uma língua dominada, isto é, para uma literatura que carece de certos recursos. Assim, a tradução desempenha um papel primordial no processo de unificação do campo literário. Já para as línguas chamadas fonte, a tradução oportuniza a disseminação internacional do capital literário dominante (ou central). Ao deslocar o poder e o prestígio dos grandes núcleos literários, a tradução evidencia o domínio de uma língua/literatura/cultura que reivindica a universalidade, elevando seu capital literário. Além disso, é uma maneira de divulgar e de afirmar as normas dominantes vigentes. Ao contrário do que se poderia hipotetizar, em se tratando de contextos de grandes línguas alvo, onde a tradução importa textos elaborados em "línguas pequenas" ou oriundos de literaturas menosprezadas, o intercâmbio linguístico e literário torna-se um meio de incorporar, de redirecionar obras em favor dos recursos dominantes, acarretando a valorização de seu capital frente ao campo literário universal.

Os espaços geradores de bens culturais desfrutam de uma posição dominada no centro do campo de poder apenas transitoriamente, pois por mais independentes que estejam das subordinações e das demandas exteriores, esses campos encontram-se permeados pelas sujeições dos campos abrangentes: o do lucro, o econômico e o político (BOURDIEU, 1996). Fica patente, portanto, o fato de que tais aspectos tornam-se "decisivos na determinação do número de obras traduzidas [...], bem como de quais serão as nações a receber essas obras" (ESTEVES, 2016). Podemos acrescentar que esses fatores também interferem na determinação dos títulos e dos autores a serem exportados, visando sempre os desdobramentos financeiros e simbólicos oriundos das transações. Os lucros específicos proporcionados pelo campo só podem ser sustentados pelo capital econômico a partir de sua conversão em capital simbólico. Por isso, Bourdieu afirma que

a única acumulação legítima [...] consiste em
fazer um nome, um nome conhecido e
reconhecido, capital de consagração que
implica um poder de consagrar objetos (é o
efeito de griffe ou de assinatura) ou pessoas
(pela publicação, a exposição, etc.), portanto,
de conferir valor, e de tirar os lucros dessa
operação. (BOURDIEU, 1996, p. 170)

É por essa razão que a competitividade literária gira em torno do monopólio da legitimidade, que confere o poder de dizer com soberania quem está habilitado a autointitular-se escritor ou intitular outro alguém como tal; ou até mesmo conferir o poder de consagração dos produtores ou dos produtos. Isso faz com que haja poucas editoras interessadas em publicar escritores sem reconhecimento, sem grife.

No que diz respeito ao contexto brasileiro, essas tensões não são muito diferentes. Atualmente, estamos testemunhando uma mudança a nível mundial na prática editorial. Segundo Casanova, não há apenas um movimento contínuo de concentração, que conduz para uma uniformização da produção e subtrai dos circuitos os pequenos editores mais inovadores, mas "sobretudo a 
diluição do setor da edição na indústria da 'comunicação' contribui para mudar as regras do jogo" (2002, p. 211). As editoras, enquanto estabelecimentos comerciais que precisam gerar renda para sobreviver, priorizam a publicação de quem é capaz de ser vendido. Se o autor não tem um (bom) lugar no campo literário nacional, ele praticamente inexiste ou é invisível. Se ele não vendeu em seu próprio país, como vai vender em outro? As editoras buscam crescentemente uma rentabilidade a curto prazo através da aquisição do padrão econômico americano. Acelerar a rotatividade dos estoques e engordar continuamente a quantidade de títulos disponíveis supera os princípios de investimento a longo prazo que norteavam a economia das editoras de grande porte. O novo objetivo passou a ser maior produção de títulos, com tiragens mais modestas, disponíveis por menos tempo e oferecidos a preços mais elevados. $A$ nova estratégia se estabelece por meio do que Casanova chama de tripla concentração: concentração das editoras, dos circuitos de distribuição e das redes de varejo, acarretando uma importância cada vez maior do papel dos técnicos e do setor comercial nas decisões sobre as publicações (2002, p. 212). Esses novos arranjos da produção e da distribuição, bem como a valorização dos parâmetros de lucro imediato, beneficiam o trânsito internacional dos bens editoriais criados para 0 mercado de massa. Entretanto, não podemos ser ingênuos ao ponto de tomar o fenômeno dos best-sellers como um evento recente. O diferencial contemporâneo se encontra na concepção e na propagação de novas obras, estas agora destinadas ao livre circuito internacional. Alterações na função editorial, do antigo ofício de triagem do editor - que recebia inúmeros manuscritos para avaliação e escolha - para um cargo de mentor e gerador, resultam em uma infinidade de textos publicados sob encomenda para atender uma certa demanda mercadológica (CASANOVA, 2002). Embora haja espaços com mais autonomia no campo literário, eles se encontram vigorosamente afetados pela força das imposições do comércio internacional que, ao modificar as circunstâncias de produção, acaba alterando também a forma de seu próprio produto - o texto. Os fenômenos de expansão de multinacionais editoriais e de massiva propagação dos ditos romances de sucesso mundial - que são exitosos em difundir uma imagem de criação literária mais livre - podem estar ameaçando o próprio conceito de uma literatura independente das leis comerciais. Hoje nos deparamos com uma literatura internacional, inovadora em seu formato e em suas repercussões, que transita fácil e rapidamente pelo mundo inteiro através de traduções praticamente simultâneas com recordes de venda devido a seu repertório globalizado (desnaturalizado) de fácil digestão e identificação que pode ser fruído em todos os continentes, conforme constatado em estudo sobre traduções para a língua inglesa (FERES, 2016). Essa nova forma de fluxo parece pender mais para o lado da importação-exportação comercial de bens simbólicos do que para o processo de internacionalismo literário.

\section{Forças editorias e autorais}

A constante busca por um (bom) posicionamento no espaço literário pode ser alcançada, entre outras formas, através de promoções e estratégias de marketing, que muitas vezes são irrisórias quando comparadas com os esforços depreendidos para promover escritores estrangeiros, sobretudo dos aclamados best-sellers. Analisando mais de perto, observamos que os modos de operação do universo literário revelam uma relação particular entre produtores culturais e centros dominantes. Uma submissão estrutural, que se apresenta de forma bastante desequilibrada aos diferentes escritores conforme sua posição no campo, e que se instaura por meio de duas réguas elementares, "o mercado, cujas sanções ou sujeições se exercem sobre as empresas literárias, seja diretamente, através das cifras de vendas, do número de recebimentos, etc., seja indiretamente, através dos novos postos oferecidos pelo jornalismo, a edição, a ilustração e por todas as formas de literatura industrial" (BOURDIEU, 1996, p. 65). Temos, portanto, escritores (e demais artistas) atuando não somente como solicitadores ou intercessores, mas, muitas vezes, também como genuínos grupos de pressão, empenhados em garantir para si mesmos o controle (in)direto das variadas vantagens materiais ou simbólicas ofertadas pelo Estado. Vemos, destarte, o profundo entrelaçamento entre os 
campos literário e político. Vemos uma poderosa rede de relações reunindo escritores, jornalistas, altos funcionários, burgueses, que estabelece formas (nem sempre) sutis de dominação que impossibilita ou desestimula o desmembramento completo daqueles que detém o poder e ainda os atraem para relações nebulosas. É dessa forma, por exemplo, que os consagrados salões literários, que, analisados cautelosamente, se destacam mais por excluir do que por agregar, favorecem a estruturação do campo literário como tal. Os desdobramentos da dominação estrutural também podem ser sentidos por meio da imprensa. É através de sua atuação como críticos que os escritoresjornalistas se instituem furtivamente como baliza dos produtos artísticos e literários, "autorizando-se, assim, a rebaixar tudo que os ultrapasse e a condenar todos os trabalhos capazes de colocar em discussão as disposições éticas que orientam seus julgamentos" (BOURDIEU, 1996, p. 70). Sob o pretexto de nomear e caracterizar os eventos literários, os produtores culturais têm o poder de fazer o mundo social ser visto segundo as convicções de um grupo social que praticamente dispõe do monopólio da produção discursiva desse contexto. 0 artista não segue leis, ele as impõe. Além disso, o artista exerce a função de ser seu próprio mercado, pois, juntamente com seus pares, encontram-se objetivamente bastante próximos por conta de suas tomadas de posição políticas e estilísticas; os escritores acabam conectados por relações de estima profissional recíproca, muitas vezes de amizade pessoal e com uma trajetória social muito próxima. Possuindo mais ou menos o mesmo capital econômico e cultural, escritores oriundos de posições mais centrais no seio do campo de poder, ou seja, aqueles que são filhos de membros de profissões intelectuais e/ou de prestígio, parecem apresentar mais probabilidade de ocupar uma posição homóloga no campo literário (BOURDIEU, 1996, p. 106). Essa complexa rede de influências e de poder representa outro circuito complicado de romper.

Para Bourdieu (1996), o campo literário é o local da coexistência ambivalente de duas formas de produção e de circulação que seguem lógicas opostas. Na tentativa de descrevê-las, o teórico agrupa as editoras em duas categorias de acordo com a duração de seus ciclos de produção: há as comerciais e as de arte pura. Os empreendimentos de arte pura apresentam um ciclo de produção longo, pois tem sua

economia anti-'econômica' da arte pura que, baseada no reconhecimento indispensável dos valores de desinteresse e na denegação da 'economia' (do 'comercial') e do lucro 'econômico' (a curto prazo), privilegia a produção e suas exigências específicas, oriundas de uma história autônoma, essa produção que não pode reconhecer outra demanda que não a que ela própria pode produzir, mas apenas a longo prazo, está orientada para a acumulação de capital simbólico, como capital 'econômico' denegado, reconhecido, portanto legítimo, verdadeiro crédito, capaz de assegurar, sob certas condições e a longo prazo, lucros 'econômicos'. (BOURDIEU, 1996, p. 163)

Já os empreendimentos ditos comerciais apresentam um ciclo de produção curto, pois seus produtos suprem uma demanda preexistente, seguem formas preestabelecidas e seguem a

lógica 'econômica' das indústrias literárias e artísticas que, fazendo do comércio dos bens culturais um comércio como os outros, conferem prioridade à difusão, ao sucesso imediato e temporário, medido, por exemplo, pela tiragem, e contentam-se em ajustar-se à demanda preexistente da clientela. (BOURDIEU, 1996, p. 163)

Observamos, portanto, de um lado, aquelas editoras que optam por vender menos quantidade, mas o que se considera "mais qualidade"; e do outro lado, aquelas editoras que optam por vender o que se considera "menos qualidade", mas mais quantidade. Ainda, em um polo, empreendimentos com ciclo de produção curto, que buscam reduzir os riscos (financeiros)

por um ajustamento antecipado à demanda
detectável, e dotados de circuitos de
comercialização e de procedimentos de
valorização (publicidade, relações públicas,
etc.) destinados a assegurar o recebimento
acelerado dos lucros por uma circulação
rápida de produtos reservados a uma
obsolescência rápida. (BOURDIEU, 1996, p.
163)

No outro polo, empreendimentos cujos ciclos de produção são do tipo

longo, baseado na aceitação do risco inerente aos investimentos culturais e sobretudo na 
submissão às leis específicas do comércio de arte: não tendo mercado no presente, essa produção inteiramente voltada para o futuro tende a constituir estoques de produtos sempre ameaçados de recair no estado de objetos materiais. (BOURDIEU, 1996, p. 163)

Dessa maneira, as editoras, a fim de assegurar seus lucros, estão constantemente avaliando o crédito dos escritores, valiosas peças nesse jogo em que muitas cartas parecem ser marcadas. Equacionar as tensões entre qualidade e quantidade (da ótica mais mercadológica da questão) pode criar apreensão, pois muitos escritores buscam obter reconhecimento por seus atributos literários em um campo onde essa qualidade é, via de regra, ditada pela quantidade. Obviamente, não podemos nos precipitar e crer que todos os escritores desfrutam das mesmas ambições profissionais. Certamente, deve haver aqueles autores que se consideram realizados com sucessos efêmeros de larga vendagem. Tudo depende da estratégia desenvolvida por cada profissional/editora.

Poderíamos, então, classificar as distintas casas editoriais de acordo com a participação que encaminham aos investimentos (de maior risco) de longo prazo e aos investimentos (mais seguros) de curto prazo e, igualmente, conforme a parcela, entre seu rol de autores, de profissionais destinados ao longo e ao curto planejamento. Os estabelecimentos de ciclo curto costumam apostar em autores que são consumidos em grandes quantidades e em pouco tempo, enquanto que os de ciclo longo preferem jogar suas fichas naqueles que vendem em menores quantidades, mas por mais tempo. Vemos a contraposição de grandes empresas com mais de 500 funcionários que conseguem publicar anualmente um número significativo (aproximadamente 200) de novas obras e claramente direcionadas para o resultado financeiro; e vemos também empresas modestas, às vezes completamente artesanais, com uma dúzia de funcionários, que lança cerca de vinte obras ao ano, destinando uma mínima parte de seu orçamento para publicidade. A importância dos gastos e a apreensão mutuamente dependente do rendimento do patrimônio, levam as grandes sociedades de capital aberto a rodar seu capital rapidamente, conduzindo abertamente tanto sua política cultural quanto a seleção dos manuscritos.
Assim, temos empresas (de produção de ciclo curto) fortemente subordinadas a grupos de agentes e instituições promotoras que precisam ser continuamente preservados e regularmente acionados. Por sua vez, o editor modesto, com a junção de assessores que também são escritores da casa, pode relacionar-se pessoalmente com o grupo dos escritores de suas publicações. Os modos de operação empregados nos trâmites com a imprensa são absolutamente ajustados às demandas do espaço mais autônomo do campo, espaço que denega o compromisso temporal e costuma contrapor êxito comercial ao mérito artístico. Para Bourdieu, o sucesso comercial (econômico) e também simbólico desse tipo de ciclo de produção (ao menos inicialmente) passa pelo papel de revelação desempenhado por determinados escritores e críticos, que têm o poder de conferir crédito à editora (1996, p. 168). O sistema educacional também exerce essa função, pois é a única instituição com a capacidade de prover, a longo prazo, um público doutrinado.

Aqueles editores e autores orientados para 0 consumo rápido e para seu público cativo veem no sucesso seu valor assegurado, fazendo com que o sucesso leve a mais sucesso. No que se refere aos bestsellers, o êxito é garantido a partir da publicação de suas tiragens; a previsão do sucesso anunciada pelos críticos é a melhor receita para o êxito de um livro ou de uma peça. O que é dito sobre uma obra não é somente um auxílio, fadado a facilitar sua compreensão e fruição, mas é, sobretudo, uma etapa de construção do texto, de seu sentido, de sua alocação no sistema literário e, particularmente, de seu valor. Essas ponderações explicam, em parte, por que muitas editoras, sobretudo as de grande porte, encontram no mercado estrangeiro uma forte fonte de proventos, atuando muito mais como compradoras (de títulos estrangeiros) do que como vendedoras (de títulos nacionais). No contexto literário brasileiro, essa dinâmica, proporcionalmente, reduz o prestígio dos autores locais, já que, na maioria das vezes, são preteridos pelos escritores estrangeiros. Embora haja posições relativas na chamada República Mundial das Letras, nota-se que a primeira situação vai de encontro à segunda e ambas podem ser tanto causa quanto efeito da parca promoção de nossos autores (principalmente 
dos contemporâneos) e do diminuto interesse das editoras brasileiras por nossas obras. Entretanto, não podemos ser ingênuos e creditar às editoras toda $a$ responsabilidade por essa conjuntura. É necessário termos em mente que a opção por certo local de publicação (editora, revista, jornal, periódico) é determinante, pois cada escritor, modo de produção ou de produto ajusta-se a uma posição natural, quer ela já exista ou precise ser criada, no campo de produção e também porque tanto os produtores quanto os produtos que se encontram "deslocados" de sua posição apropriada (segundo as regras do jogo literário), parecem estar mais propensas ao fracasso (BOURDIEU, 1996, p. 190). O responsável por produzir o valor da obra não é o autor, mas o campo de produção na qualidade de espaço de crença que gera o valor da obra como fetiche (BOURDIEU, 1996, p. 259).

A crítica e a mídia, nas condições de formadoras e pulverizadoras de opiniões, têm o poder de valorizar o passe dos autores e enquadrá-los como mais propícios para ciclos curto ou longo. É pertinente sublinhar que, frequentemente, os autores atuam em diferentes frentes dos processos de produção (FERES, 2016), pois possuem "acesso a posições de poder nas instâncias de consagração e de legitimação [...] ou nas instâncias de reprodução e de legitimação" (BOURDIEU, 1996, p. 175), ou seja, podem ser considerados tanto parte da instituição quanto do mercado (EVEN-ZOHAR, 1990). Esse tipo de relação de mão dupla tem o poder de validar e consolidar autores e obras facilitando seus acessos a posições mais centrais no polissistema literário. Ademais, o escritor que cria sua arte é ele mesmo gerado, no interior do campo de produção, pela soma dos que auxiliaram na sua revelação e consagração, daqueles que o empurraram até a condição de (re)conhecido, isto é, os críticos, promotores culturais, prefaciadores, etc. Afinal, a obra (literária ou artística) só passa a existir na condição de objeto simbólico munido de valor quando conhecida e reconhecida, isto é, socialmente declarada como tal (obra literária ou artística) por expectadores investidos da aptidão e da competência estéticas necessárias para perceber e identificar como tal. Após atingir o patamar de reconhecimento, sua arte pode ser capaz de endossar-Ihe uma carreira promissora, destacada por diversos benefícios e promoções, como prêmios literários, medalhas ou cargos, culminando no acesso a posições de poder nas esferas de produção, de consagração ou de legitimação. Assim, temos que os resultados esperados no sentido de uma mudança dessa dinâmica dependem de ações coordenadas de um conjunto composto "pela família, pelo Estado e pela sociedade civil", cabendo ao Estado "os investimentos a longo prazo em educação, o empenho na formação de professores e mediadores de leitura, os esforços para a implementação do Plano Nacional do Livro e Leitura (PNLL) e o fortalecimento do sistema de bibliotecas públicas" (FAILLA, 2016).

O lugar, portanto, que um país ocupa na "República das Letras" é resultado do saldo de reconhecimento de seus escritores (e de alguns em particular), assim como do número de traduções feitas de seus autores e do valor alcançado na crítica estrangeira. O portal Index Translationum é, apesar de suas limitações, uma ferramenta disponível para mensurar a participação e a posição dos países na República. Como anteriormente mencionado, a análise dos números referentes ao idioma de origem das traduções evidencia a absoluta supremacia do inglês, que lidera, com folga do segundo colocado, o francês. Essa hegemonia, como sabemos, não ocorre somente no contexto editorial. É apenas uma das manifestações de seu poder econômico, político, cultural e, até mesmo, bélico. Afinal, a língua, em todas as suas manifestações, é demonstração de poder (BOURDIEU, 1983; RAJAGOPALAN, 1997; SPIVAK, 2000).

\section{Considerações finais}

Nesse sentido, embora existam ações que difundem a cultura e literatura brasileiras no exterior como o Programa de Apoio à Tradução e à Publicação de Autores Brasileiros no Exterior -, não há como negar que nosso país, representado pelos autores, por suas obras e pela língua portuguesa, entra nas disputas por centralidade/capital simbólico no campo literário praticamente na condição de azarão. Cada país apresenta as armas de que dispõe. Even-Zohar (1999) considera que há dois pontos cruciais nesse jogo por 
poder: critérios de seleção das obras a serem traduzidas e a forma como as traduções são conduzidas. Ambas as questões desvelam intricadas relações entre sistemas de partida e de chegada. Tanto Even-Zohar (1990) quanto outros autores (TOURY, 1995; VENUTI, 1995; 2002) defendem que esses movimentos são ideológicos, ou seja, obedecem a regras e valores bem específicos, conforme evidenciado nos parágrafos anteriores a partir das teorizações de Bourdieu, Even-Zohar e Casanova e suas intersecções. Por isso é tão importante acompanharmos nossa literatura e a gama de obras brasileiras que está recebendo incentivo para chegar aos demais países. Podemos, assim, conhecer mais a respeito da configuração dessas relações, bem como suas implicações, pois, segundo Even-Zohar, a literatura não é tomada como uma atividade isolada dentro de uma sociedade, cuja regulação obedece a regras exclusivas e inerentes desse âmbito, completamente distintas das demais atividades humanas. A literatura é concebida como um aspecto integrante - frequentemente central $\mathrm{e}$ com muito poder - em uma sociedade (EVEN-ZOHAR, 1990, p. 2).

A conexão e os padrões de interação dos diferentes subcampos que compõem o campo literário podem ser valiosas fontes de insumo para melhor compreender a atuação de políticas de tradução e suas relações com a leitura no sistema nacional. Investir nas discussões acerca de políticas de tradução nos ajuda a compreender os encadeamentos existentes entre 0 sistema que exporta traduções e o sistema que as importa, assim como entre esses subsistemas e o polissistema que os abrange. Analisando o fluxo de obras traduzidas tanto em seu sistema de partida quanto de chegada, podemos formular hipóteses acerca da composição do polissistema, das forças nele exercidas (e por ele exercidas) e dos fatores políticos e ideológicos nele embutidos. Podemos fazer inferências a respeito do impacto dessas ações na validação e consolidação de nossos autores em território nacional. É dentro dessa perspectiva que a tradução é aqui proposta. Ela é concebida não somente como o processo de substituição de um signo linguístico por outro, mas como uma ação mais abrangente, complexa, dinâmica e historicamente construída, que se inicia na seleção da obra a ser traduzida.

\section{Referências}

BOURDIEU, P. A economia das trocas linguísticas. n. 34, maio 1977. Trad. Paula Montero. In: ORTIZ, Renato (Org.). Bourdieu - Sociologia. São Paulo: Ática, 1983. Coleção Grandes Cientistas Sociais, v. 39. p. 156-183. Disponível em: $\quad<\mathrm{http}$ ://antropologias.descentro.org/bibliotecavirtual/todo-o-acervo-de-antropologiasunicamp?did=4245> . Acesso em: 17 fev. 2017.

BOURDIEU, P. As regras da arte: gênese e estrutura do campo literário. Tradução de. Maria Lucia Machado. São Paulo: Companhia das Letras, 1996.

BRASIL. Plano Nacional do Livro e Leitura PNLL/Ministério da Educação e Ministério da Cultura. Brasília, DF. 2006. Edição atualizada e revisada em 2014. Disponível

em: <http://www.cultura.gov.br/documents/10883/1171222/cade rnoPNLL_2014ab.pdf/df8f8f20-d613-49aa-94f5edebf1a7a660>. Acesso em: 19 fev. 2017.

CASANOVA, P. A república Mundial das Letras. Tradução de Marina Appenzeller. São Paulo: Estação Liberdade, 2002.

ESTEVES, L. M. R. A presença da literatura brasileira no exterior e a importância do agenciamento: uma análise guiada por conceitos da sociologia de Pierre Bourdieu. 0 eixo e a roda, Belo Horizonte, n.1, v.25, 2016, p. 9-36.

EVEN-ZOHAR, I. Polysystem studies. Poetics Today. Durham: Duke University Press, v.11, n.1, 1990.

FAILLA, Zoara (org.) Retratos da leitura no Brasil 4. São Paulo: Instituto Pró-Livro e Imprensa Oficial do Estado de São Paulo, 2016. Disponível em: <http://prolivro.org.br/home/images/2016/RetratosDaLeitura 2016_LIVRO_EM_PDF_FINAL_COM_CAPA.pdf> Acesso em: 17 fev. 2017 .

FERES, L. A cultura traduzida e a cultura em tradução: a literatura brasileira contemporânea na revista Granta. 2016. 144 f. Dissertação (Mestrado) - Centro Universitário Ritter dos Reis, Programa de Pós-Graduação em Letras, Porto Alegre, 2016.

RAJAGOPALAN, K. Linguistics and the myth of nativity: comments on the controversy over 'new/non-native' Englishes. Journal of Pragmatics, n.27, p. 225-231, 1997.

SONCELLA, J. B. M. Valor simbólico e leitura: a tradução da leitura francesa no Brasil. 2012. 214 f. Tese (Doutorado) - Universidade Estadual de Londrina, Centro de Letras e Ciências Humanas, Programa de Pós-Graduação em Letras, Londrina. 2012.

SPIVAK, G. C. The politics of translation. In: VENUTI, L. (Org.). The translation studies reader. London/New York: Routledge, 2000, p. 397-416.

TOURY, G. Introduction: A Case for Descriptive Translation Studies; The Nature and Role of Norms in Translation. In: Descriptive Translation Studies and Beyond. 
Amsterdam/Philadelphia: John Benjamins, 1995, p. 1-4; 5359.

UNESCO. Index Translationum: World bibliography of translation. www.unesco.org/culture/xtrans/. Acesso em: 19 fev. 2017.

VENUTI, L. Os escândalos da tradução. Trad. Laureano Pelegrin, Lucinéia Villela, Marileide Esqueda e Valéria Biondo. Bauru: EDUSC, 2002.

VENUTI, L. The translator's invisibility: a history of BRISOLARA, Valeria; FERES, Lilia Baranski. Literatura, tradução e cultura: intersecções teóricas sob um olhar sistêmico. Signo, Santa Cruz do Sul, v. 46, n. 87, sep. 2021. ISSN 1982-2014. Disponível em:

$<$ https://online.unisc.br/seer/index.php/signo/article/view/146 >. Acesso em: 10 sep. 2021.

doi:https://doi.org/10.17058/signo.v46i87.16670.translation. London/New York: Routledge, 1995.

BRISOLARA, Valeria; FERES, Lilia Baranski. Literatura, tradução e cultura: intersecções teóricas sob um olhar sistêmico. Signo, Santa Cruz do Sul, v. 46, n. 87, sep. 2021. ISSN 1982-2014. Disponível em: <https://online.unisc.br/seer/index.php/signo/article/view/146>. Doi:https://doi.org/10.17058/signo.v46i87.16670. 